\title{
Study of active controlled monotherapy used for rheumatoid arthritis, an IL-6 inhibitor (SAMURAI): evidence of clinical and radiographic benefit from an $x$ ray reader-blinded randomised controlled trial of tocilizumab
}

\author{
Norihiro Nishimoto, Jun Hashimoto, Nobuyuki Miyasaka, \\ Kazuhiko Yamamoto, Shinichi Kawai, Tsutomu Takeuchi, \\ Norikazu Murata, Désirée van der Heijde, Tadamitsu Kishimoto
}

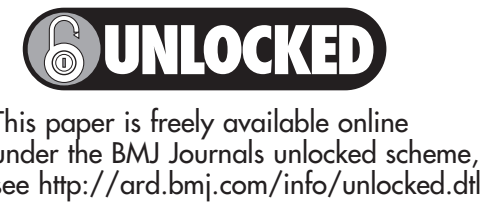

Ann Rheum Dis 2007;66:1 162-1167. doi: 10.1136/ard.2006.068064

See end of article for authors' affiliations

Correspondence to: Norihiro Nishimoto, MD, Laboratory of Immune Regulation, Graduate School of Frontier Biosciences, Osaka University 1-3, Yamada-oka, Suita, Osaka, 565-0871, Japan; norihiro@f́bs.osaka-u.ac.jp

Accepted 14 April 2007 Published Online First 8 June 2007
Objective: To evaluate the ability of tocilizumab (a humanised anti-IL-6 receptor antibody) monotherapy to inhibit progression of structural joint damage in patients with RA.

Methods: In a multi-centre, $x$ ray reader-blinded, randomised, controlled trial, 306 patients with active RA of $<5$ years' duration were allocated to receive either tocilizumab monotherapy at $8 \mathrm{mg} / \mathrm{kg}$ intravenously every 4 weeks or conventional disease-modifying antirheumatic drugs (DMARDs) for 52 weeks. Radiographs of hands and forefeet were scored by the van der Heijde modified Sharp method.

Results: Patients had a mean disease duration of 2.3 years and a disease activity score in 28 joints of 6.5 at baseline. Mean total modified Sharp score (TSS) was 29.4, which was very high despite the relatively short disease duration. At week 52 , the tocilizumab group showed statistically significantly less radiographic change in TSS (mean 2.3; 95\% Cl 1.5 to 3.2) than the DMARD group (mean 6.1; 95\% Cl 4.2 to 8.0; $\mathrm{p}<0.01$ ). Tocilizumab monotherapy also improved signs and symptoms. The overall incidences of AEs were $89 \%$ and $82 \%$ (serious AEs: $18 \%$ and $13 \%$; serious infections: $7.6 \%$ and $4.1 \%$ ) in the tocilizumab and DMARD groups, respectively.

Conclusion: Tocilizumab monotherapy was generally well tolerated and provided radiographic benefit in patients with RA.
$\mathrm{R}$ heumatoid arthritis (RA) is a chronic inflammatory disease characterised by persistent synovitis and destruction of bone and cartilage in multiple joints. ${ }^{1}$ Although etiological causes are still obscure, constitutive overproduction of interleukin-6 (IL-6), a pleiotropic cytokine that regulates the immune response, inflammation, hematopoiesis, and bone metabolism, is thought to play a pathological role in RA. ${ }^{2}$ Overproduction of IL-6 augments autoimmune reaction and causes systemic inflammatory manifestations. IL-6, synergistically with IL- $1 \beta$ or TNF $\alpha$, induces the production of vascular endothelial growth factor, a potent inducer of angiogenesis necessary to oxygenate the hyperplastic synovial tissues in the affected joints. ${ }^{3}$ IL- 6 in the presence of soluble IL- 6 receptor induces osteoclast differentiation and can be responsible for joint destruction and osteoporosis associated with RA. ${ }^{4}$ In fact, elevated IL-6 levels are observed in serum and synovial fluid in RA patients ${ }^{6-10}$ and correlate with disease activity and radiological joint damage. ${ }^{51-14}$ IL-6 levels also correlate with levels of matrix metalloproteinase $3,{ }^{15}$ which degrades the proteoglycan of cartilage and also predicts radiological progression. ${ }^{15-17}$

Tocilizumab, a humanised anti-IL-6 receptor (IL-6R) monoclonal antibody, ${ }^{18}$ has been shown to improve the symptoms of RA in previous clinical trials. ${ }^{19-22}$ However, there is no study to date that investigates the potential of tocilizumab in inhibiting joint damage and improving disability, which are also important therapeutic endpoints.

To investigate whether tocilizumab monotherapy provides radiographic and clinical benefits to active RA patients, we conducted a multi-centre, $x$ ray reader-blinded, randomised, controlled study.

\section{METHODS}

\section{Patients}

Eligible patients were age $>20$ years and fulfilled the American College of Rheumatology (ACR; formerly, the American Rheumatism Association) 1987 revised criteria for the classification of $\mathrm{RA}^{23}$ with a disease duration of $\geqslant 6$ months and $<5$ years. In addition, they had $\geqslant 6$ tender joints (of 49 evaluated), $\geqslant 6$ swollen joints (of 46 evaluated), an erythrocyte sedimentation rate (ESR) of $\geqslant 30 \mathrm{~mm} / \mathrm{h}$ and C-reactive protein (CRP) of $\geqslant 20 \mathrm{mg} / \mathrm{l}$. All candidates had an inadequate response to at least one disease modifying antirheumatic drug (DMARD) or immunosuppressant. Use of anti-TNF agents and leflunomide were not allowed within 3 months prior to the first dose. Change in dose and type of DMARDs and/or immunosuppressants, plasma exchange therapies and surgical treatments were not allowed within 4 weeks. Oral corticosteroids (prednisolone, $\leqslant 10 \mathrm{mg}$ per day) were allowed if the dosage had not been changed within 2 weeks. Eligible patients had white blood cell counts of at least $3.5 \times 10^{9} /$, lymphocyte counts of at least $0.5 \times 10^{9}$ / $\mathrm{l}$ and platelet counts of at least $100 \times 10^{9} / 1$ at enrolment. Patients were excluded if they had a medical history of a serious allergic reaction, significant concomitant diseases, or an active intercurrent infection requiring medication within 4 weeks before the first dose. Sexually active premenopausal women were required to have a negative urine pregnancy test at the entry and to use effective contraception during the study period.

\section{Study protocol}

This study was conducted at 28 sites in Japan. The study protocol was approved by the Ministry of Health, Labor and 


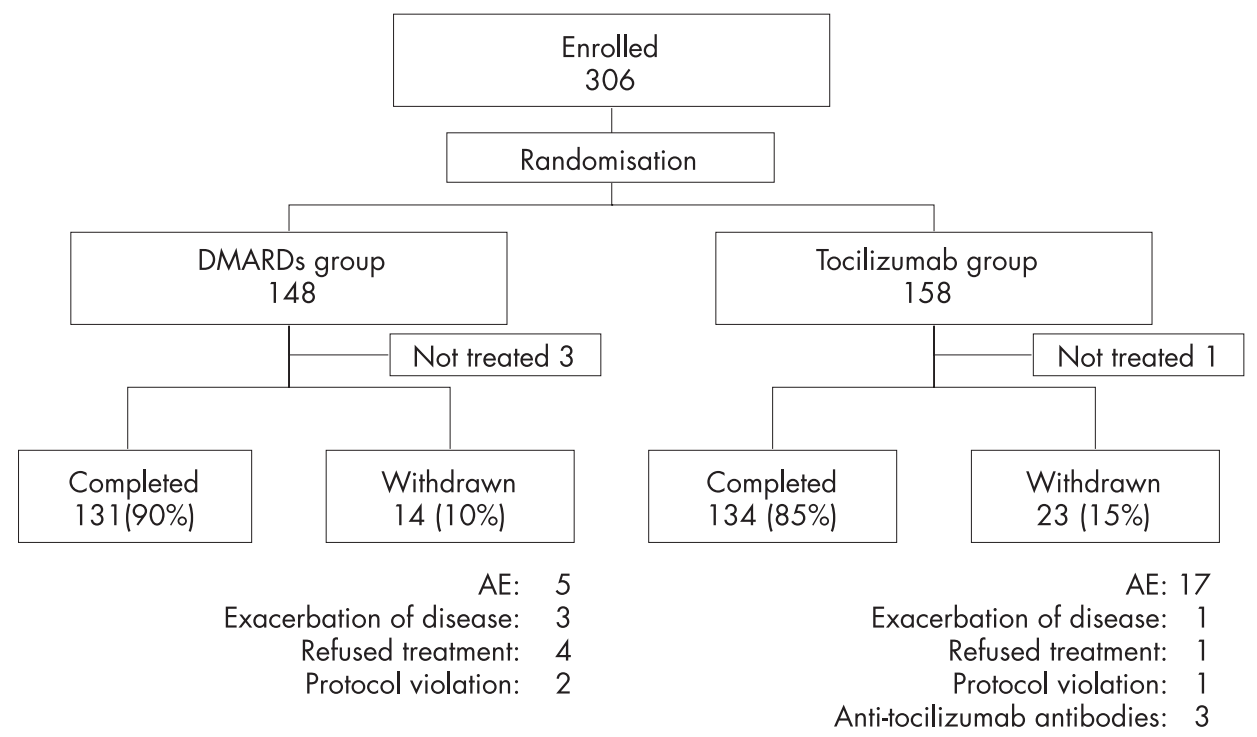

Figure 1 Randomisation, reasons for withdrawal, and numbers of patients who completed the trial. DMARDs, diseasemodifying antirheumatic drugs; Tocilizumab, humanised anti-interleukin- 6 receptor antibody.

Anti-tocilizumab antibodies: 3

Welfare of Japan, and by the local ethical committee, and patients gave their written informed consent. This trial was registered with http://clinical trials.gov (NCT00144508).

Patients were randomly assigned to receive either tocilizumab monotherapy at $8 \mathrm{mg} / \mathrm{kg}$ intravenously every 4 weeks or conventional DMARD therapy for 52 weeks. A long-term placebo-controlled study in RA patients with highly active disease was not acceptable from an ethical point of view, and therefore DMARDs were used for the controls. The randomisation was performed by registering of patients at the patient registration centre with a centralised allocation method. For the tocilizumab group, DMARDs and/or immunosuppressants were discontinued from the start of the study. Oral corticosteroids ( $\leqslant 10 \mathrm{mg}$ prednisolone per day) were allowed, but the dosage could not be increased during the study. Intra-articular corticosteroid injections were not allowed. Use of one nonsteroidal anti-inflammatory drug (NSAID), including switching to another NSAID, was allowed. For the conventional DMARD group, the dose, type and combination of DMARDs and/or immunosuppressants, except for anti-TNF agents and leflunomide, could be varied according to disease activity at the discretion of the treating physician. Variations of NSAIDs and/ or corticosteroids including intra-articular corticosteroid injections were also allowed. Surgical treatment and use of bisphosphonates was not allowed in either group. Safety was assessed through recording of adverse events, physical examinations, and standard laboratory tests for both groups.

\section{Radiographic and clinical assessment}

Posteroanterior radiographs of hands and anteroposterior radiographs of feet were performed at baseline, week 28 and week 52 or at the last visit for patients who withdrew from the study prior to week 52. For patients who dropped out before week 52, missing radiograph values at week 52 were estimated by linear extrapolation using data at baseline, week 28 and the early termination visit. Radiographs were scored using van der Heijde's modified Sharp method ${ }^{24} 25$ independently by two readers who were well trained and competent to score radiographs. The readers were blinded to the treatment group, chronologic order of the films and clinical response of each patient. Ten percent of the patients' films were re-read for the analysis of intra-reader variability.

ACR20, 50 and 70 responses, and disease activity score in 28 joints (DAS28) were assessed for clinical improvement of RA using an intent-to-treat (ITT) analysis.

\section{Statistical analysis}

A sample size of 120 patients per treatment group was estimated to provide $80 \%$ power for detecting a significant $(p<0.05)$ difference in mean change score of radiographic findings between the tocilizumab and DMARD groups. We decided to recruit 150 patients per treatment group to allow for anticipated withdrawals. Radiographic endpoints, such as TSS, erosion score and joint space narrowing score, were assessed with a rank transformed analysis of covariance (ANCOVA) on the change scores that included factors for baseline score and baseline disease duration. The incidences of clinical improvements were analysed by the chi-square test.

All statistical analyses were two-sided and $\mathrm{p}$ values less than 0.05 were considered significant. All patients receiving at least one dose of study drug were included in the efficacy and safety analysis.

\section{RESULTS}

\section{Characteristics of the patients}

This study enrolled 306 patients in total (Figure 1). Four patients were withdrawn before treatment either due to their ineligibility or at the patients' request. A total of 302 patients received study drugs. A total of 134 patients in the tocilizumab group and 131 patients in the DMARDs group completed 52 weeks treatment. Discontinuation occurred in 23 patients in the tocilizumab group and 14 patients in the DMARDs group. The reported reasons for withdrawal are shown in Figure 1.

Demographics and baseline disease characteristics did not differ between the two groups (Table 1).

Mean disease duration was 2.3 years. Patients had active disease, indicated by a DAS28 score of 6.5 and CRP of $48 \mathrm{mg} / \mathrm{L}$ at baseline. Moreover, TSS at baseline was 29.4, which was very high despite the relatively short disease duration. The mean estimated yearly progression rate, calculated from the baseline TSS divided by disease duration for each patient, was 13.3 Sharp units.

\section{Treatment in the conventional DMARD group}

At baseline, 67\% of the patients in the DMARDs group received methotrexate (MTX): $37 \%$ received a combination of MTX and DMARDs, 30\% received MTX monotherapy, and 22\% received DMARDs and/or immunosuppressants other than MTX, besides corticosteroids. The dose of MTX was $7.1 \pm 1.9 \mathrm{mg} /$ week $($ mean $\pm S D)$ in patients treated with MTX. During the study, 123 patients (85\%) received MTX: 81 (56\%) received a 
Table 1 Patient demographics and clinical characteristics at baseline*

\begin{tabular}{|c|c|c|}
\hline & $\begin{array}{l}\text { Conventional } \\
\text { DMARDs } \\
\text { ( } n=145 \text { ) }\end{array}$ & $\begin{array}{l}8 \mathrm{mg} / \mathrm{kg} \\
\text { Tocilizumab } \\
\text { ( }=157 \text { ) }\end{array}$ \\
\hline \multicolumn{3}{|l|}{ Demographics } \\
\hline $\begin{array}{l}\text { Age, years } \\
\text { Male:female ratio }\end{array}$ & $\begin{array}{l}53.1 \pm 12.5 \\
26: 119\end{array}$ & $\begin{array}{l}52.9 \pm 11.6 \\
32: 125\end{array}$ \\
\hline \multicolumn{3}{|l|}{ Clinical characteristics } \\
\hline RA duration, years & $2.4 \pm 1.3$ & $2.2 \pm 1.4$ \\
\hline No. of failed DMARDs, mean (range) & $2.8 \overline{(1-7)}$ & $2.7(1-7)$ \\
\hline Functional Classt, I:II:III:IV & $11: 114: 20: 0$ & $12: 126: 19: 0$ \\
\hline RA Staget, I:II:III:IV & $18: 57: 51: 19$ & $14: 77: 46: 20$ \\
\hline Tender joint count, $0-49$ scale & $14.4 \pm 7.2$ & $15.3 \pm 7.3$ \\
\hline Swollen joint count, 0-46 scale & $11.9 \pm 5.5$ & $12.5 \pm 6.4$ \\
\hline $\mathrm{ESR}, \mathrm{mm} / \mathrm{h}$ & $71.0 \pm 25.2$ & $70.8 \pm 27.9$ \\
\hline CRP, $\mathrm{mg} / \mathrm{L}$ & $49 \pm 29$ & $47 \pm 29$ \\
\hline DAS28 & $6.4 \pm 0.9$ & $6.5 \pm 0.8$ \\
\hline \multicolumn{3}{|l|}{ Radiographic findings } \\
\hline Modified TSS, $0-448$ scale & $30.6 \pm 42.0$ & $28.3 \pm 43.9$ \\
\hline Erosion score, 0-280 scale & $13.9 \pm 21.7$ & $13.8 \pm 24.6$ \\
\hline $\begin{array}{l}\text { Joint space narrowing score, 0-168 } \\
\text { scale }\end{array}$ & $16.7 \pm 21.8$ & $14.5 \pm 20.8$ \\
\hline Estimated annual TSS progression & $12.3 \pm 16.2$ & $14.1 \pm 26.9$ \\
\hline Treatment classification & & \\
\hline $\begin{array}{l}\text { MTX and at least one DMARD, } \\
\text { patients (\%) }\end{array}$ & $53(37)$ & $43(27)$ \\
\hline MTX monotherapy, patients (\%) & $44(30)$ & $73(46)$ \\
\hline $\begin{array}{l}\text { DMARDs/immunosuppressants, } \\
\text { patients (\%) }\end{array}$ & $32(22)$ & $30(19)$ \\
\hline MTX dose, $\mathrm{mg} /$ week & $7.1 \pm 1.9$ & $6.9 \pm 2.0$ \\
\hline $\begin{array}{l}\text { Prednisolone equivalent corticosteroid } \\
\text { dose, } \mathrm{mg} / \text { day }\end{array}$ & $5.4 \pm 3.2$ & $5.4 \pm 3.1$ \\
\hline
\end{tabular}

*Except where indicated otherwise, values are the mean \pm SD. tRA functional status determined by American College of Rheumatology criteria. RA stage determined by Steinbrocker's criteria.

DMARDs, disease-modifying antirheumatic drugs; Tocilizumab, humanised anti-interleukin-6 receptor antibody; RA, rheumatoid arthritis; ESR, erythrocyte sedimentation rate; CRP, C-reactive protein; DAS28, Disease Activity Score in 28 joints; TSS, total Sharp score; MTX, methotrexate.

combination of MTX and DMARDs, 42 (29\%) received MTX monotherapy, and 20 (14\%) received DMARDs and/or immunosuppressants other than MTX, besides corticosteroids. The dose of MTX was $8.0 \pm 2.1 \mathrm{mg} /$ week in patients treated with MTX (Japanese government recommends 6-8 mg/week of MTX based on the evidence from the Japanese clinical trial of MTX for RA). ${ }^{26}{ }^{27}$ Besides MTX, salazosulfapyridine (41\%), bucillamine $(23 \%)$, mizoribine $(8 \%)$ and D-penicillamine $(8 \%)$ were frequently used in more than $5 \%$ of the patients.

\section{Reliability of radiographic scoring}

Intra-reader intraclass correlation coefficients for erosion, joint space narrowing and TSS were all 0.99 for both readers. Interreader intraclass correlation coefficients for erosion, joint space narrowing and TSS were $0.98,0.96$ and 0.98 , respectively.

\section{Radiographic evaluation of joint damage}

Figure 2 shows the cumulative probability plots of the change from baseline to week 52 in the TSS. The space between the curves indicates different treatment effects with a considerable difference in favour of the tocilizumab monotherapy group. The plots representing the TSS changes in the tocilizumab group clearly shifted to the right compared with those in the conventional DMARDs, indicating that fewer patients in the tocilizumab group showed radiographic progression and also a smaller amount of progression than those in the DMARDs group. At week 52, 56\% of patients receiving tocilizumab had no radiographic progression (i.e., change from baseline in the TSS $\leqslant 0.5)$ compared with $39 \%$ of patients receiving conventional DMARDs $(\mathrm{p}<0.01)$. Moreover, more patients receiving

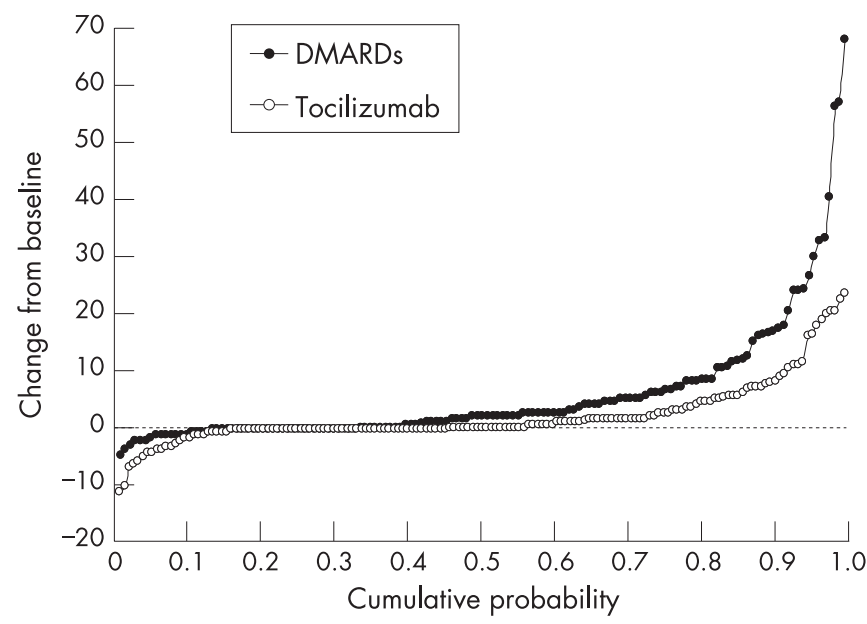

Figure 2 Cumulative probability distribution of radiographic changes in total Sharp/van der Heijde scores from baseline to week 52 for patients treated with tocilizumab or with conventional DMARDs. The space between the curves indicates the different treatment effects with a considerable difference in favour of the tocilizumab group.

tocilizumab monotherapy had negative TSS scores than those receiving conventional DMARDs ( 24 patients and 18 patients at week 52, respectively).

The mean changes in the TSS as well as erosion scores at week 28 were statistically significantly less in the tocilizumab group than in the DMARDs group with an ANCOVA model (Table 2).

The efficacy was more evident at week 52. In addition to the TSS and erosion score, joint space narrowing scores also showed significantly less change in the tocilizumab group than in the DMARD group. In the tocilizumab group, patients who achieved a higher ACR response showed less radiological progression at week 52 (in the patients with ACR70 response $(\mathrm{n}=73)$, mean TSS $1.6 ; 95 \%$ CI 0.3 to 2.8$)$. A similar effect was observed in the DMARDs group (in the patients with ACR70 response $(n=8)$, mean TSS $1.5 ; 95 \%$ CI -0.6 to 3.6$)$.

Table 2 Change in radiographic scores

$\begin{array}{ll}\text { Conventional } & 8 \mathrm{mg} / \mathrm{kg} \\ \text { DMARDs }(n=143) & \text { Tocilizumab } \\ (n=157)\end{array}$

\begin{tabular}{|c|c|c|}
\hline Week 28 & & \\
\hline Total Sharp score & & \\
\hline Mean $(95 \% \mathrm{Cl})$ & $4.5(3.1$ to 6.0$)$ & $1.9(1.2 \text { to } 2.6)^{*}$ \\
\hline Median (IQR) & $1.0(0.0$ to 5.0$)$ & $0.5(0.0$ to 2.0$)$ \\
\hline Erosion score & & \\
\hline Mean $(95 \% \mathrm{Cl})$ & 2.4 (1.6 to 3.2 ) & $0.8(0.4$ to 1.2$) \dagger$ \\
\hline Median (IQR) & $0.5(0.0$ to 2.5$)$ & $0.0(0.0$ to 1.0$)$ \\
\hline Joint space narrow & & \\
\hline Mean $(95 \%$ CI) & $2.2(1.4$ to 2.9$)$ & $1.1(0.7$ to 1.6$)$ \\
\hline Median (IQR) & $0.0(0.0$ to 2.0$)$ & $0.0(0.0$ to 1.0$)$ \\
\hline Week 52 & & \\
\hline Total Sharp score & & \\
\hline Mean $(95 \%$ Cl) & 6.1 (4.2 to 8.0$)$ & $2.3(1.5$ to 3.2$) \dagger$ \\
\hline Median (IQR) & $2.5(0.0$ to 7.0$)$ & $0.5(0.0$ to 3.0$)$ \\
\hline Erosion score & & \\
\hline Mean $(95 \% \mathrm{Cl})$ & $3.2(2.1$ to 4.3$)$ & $0.9(0.3$ to 1.4$) \ddagger$ \\
\hline Median (IQR) & $1.0(0.0$ to 3.5$)$ & $0.0(0.0$ to 1.0$)$ \\
\hline Joint space narrow & & \\
\hline Mean $(95 \% \mathrm{Cl})$ & 2.9 (2.0 to 3.8 ) & $1.5(0.9 \text { to } 2.1)^{*}$ \\
\hline Median (IQR) & $1.0(0.0$ to 4.0$)$ & $0.0(0.0$ to 1.7$)$ \\
\hline
\end{tabular}

${ }^{*} \mathrm{p}<0.05, \mathrm{tp}<0.01, \neq \mathrm{p}<0.001$.

$P$ values were analysed with a rank transformed analysis of covariance (ANCOVA) on the change scores that included factors for baseline score and baseline disease duration. DMARDs, disease-modifying antirheumatic drugs; Tocilizumab, humanised anti-interleukin-6 receptor antibody; $95 \%$ $\mathrm{Cl}, 95 \%$ confidence interval; IQR, interquartile range. 


\section{Clinical efficacy}

At week 52, proportions of the patients achieving ACR20, ACR50, and ACR70 response were $78 \%, 64 \%$, and $44 \%$ in the tocilizumab group and 34\%, 13\%, and $6 \%$ in the DMARD group, respectively, indicating the superiority of tocilizumab monotherapy to conventional DMARD therapy $(\mathrm{p}<0.001$, for each comparison) although clinical efficacy was assessed unblinded (Figure 3A).

Greater reduction in DAS28 scores and higher remission rates were also observed in the tocilizumab group than in the DMARDs group (Figure 3B). At week 52, clinical remission (defined as DAS28<2.6) ) $^{28}$ was achieved in $59 \%$ of patients receiving tocilizumab, but only in $3 \%$ of patients receiving DMARDs $(\mathrm{p}<0.001)$. Major clinical response (ACR70 response for 6 consecutive months) was achieved in $24 \%$ of patients receiving tocilizumab compared with only $2 \%$ of patients receiving DMARDs during the study period of 52 weeks.

\section{Physical function and health-related quality of life}

Tocilizumab monotherapy significantly improved MHAQ scores compared to conventional DMARDs (Figure 3C). A decrease of $>0.22$ units in HAQ scores represents significant clinical improvement and the minimum clinically important difference. $^{29}$ Such improvement was seen in $40 \%$ of the patients treated with tocilizumab as early as week 4 , the first scheduled study visit, and was even more evident at week 52 (68\% in the tocilizumab group and $40 \%$ in the DMARDs group, $\mathrm{p}<0.001)$.

\section{Safety}

The percentages of patients with adverse events were $89 \%$ and $82 \%$ in the tocilizumab and DMARD groups, respectively. Most of adverse events were mild or moderate. Table 3 shows frequent adverse events observed in at least $5 \%$ of the patients.

Nasopharyngitis was the most common adverse event, but the incidences were similar in both groups.

Serious adverse events were reported in $18 \%$ and $13 \%$ in the tocilizumab group and DMARDs group, respectively. In the tocilizumab group, 12 serious infections were reported: 3 (1.9\%) patients with pneumonia, $2(1.3 \%)$ with upper respiratory tract infection, $2(1.3 \%)$ with cellulitis, $1(0.6 \%)$ each with gastroenteritis, herpes zoster, herpes simplex, perianal abscess and an unidentified infection. In the DMARD group, 8 serious infections were reported: $3(2.1 \%)$ patients with gastroenteritis, 2 (1.4\%) with pneumonia, and $1(0.7 \%)$ each with upper respiratory tract infection, herpes zoster and sepsis. All the serious adverse events improved with appropriate treatment. There was no significant prolongation of infection by the tocilizumab treatment. Tuberculosis was not observed in this 1year study without required screening or prophylactic use of any antituberculous drug.

Three malignancies were reported in the tocilizumab group: 2 patients with breast cancer (including l lobular carcinoma in situ) and 1 with colon cancer, which were improved or resolved by appropriate treatment (including surgery). No malignancies were reported in the DMARD group.

Drug-related infusion reactions were reported 14 times in 11 $(7.0 \%)$ patients of the tocilizumab group: 3 with transient increase in blood pressure, 2 with injection site redness, 2 with headache, 2 with nausea, 2 with skin eruption, and 1 each with vomiting, pruritus, and malaise. All the infusion reactions were mild, and no patient withdrew from the study as a consequence.

Laboratory test abnormalities were reported in $61 \%$ and $31 \%$ of patients in the tocilizumab and DMARD groups, respectively. In the tocilizumab group, lipid metabolism-related reactions were common. Anomalous increases in total cholesterol (TC), triglycerides, and low-density lipoprotein cholesterol were
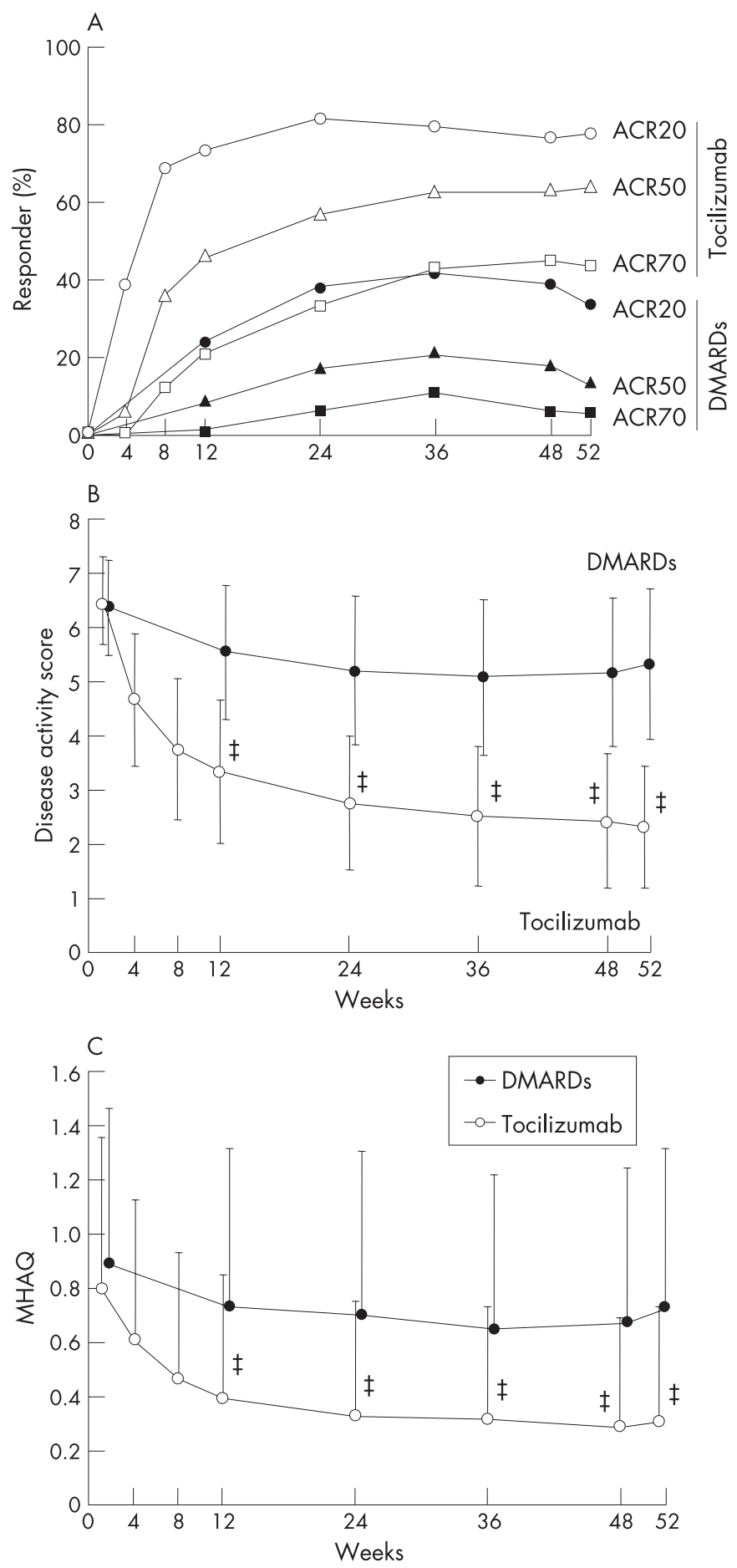

Figure 3 Percentage of responders according to the American College of Rheumatology (ACR) improvement criteria and the Disease Activity Score in 28 joints (DAS28) as well as mean change in Modified Health Assessment Questionnaire (MHAQ) scores. Percentage of responders according to the ACR improvement criteria (A) and the DAS28 (B) according to the ITT analysis over 52 weeks. Mean change in MHAQ scores from baseline to week 52 (C). $\ddagger p<0.001$ versus DMARDs by paired t-test.

reported in $38 \%, 17 \%$, and $26 \%$ of the patients, respectively, and most of them were grade 1 according to the National Cancer Institute Common Toxicity Criteria. Twenty-seven patients were treated (HMG-CoA reductase inhibitor, 26 cases; fenofibrate, 1 case) and their cholesterol levels improved during the study. Tocilizumab monotherapy also raised high-density lipoprotein cholesterol (HDLC) levels to above the normal range 
in $24 \%$ of patients. The atherogenic index, calculated by (TCHDLC)/HDLC, did not change during the study period of 52 weeks. No cardiovascular complications were observed in association with abnormal lipid profile.

Anti-tocilizumab antibodies were detected in 4 patients $(2.5 \%)$. Only one patient showed a skin eruption at the third injection, while the other three were asymptomatic. They were all withdrawn according to the study protocol.

\section{DISCUSSION}

This 52-week, $x$ ray reader-blinded, randomised, controlled trial demonstrated that tocilizumab monotherapy in patients with active RA significantly inhibited the progression of structural joint damage compared with conventional DMARDs therapy. Note that even monotherapy with tocilizumab significantly retarded the radiological progression. It is of interest whether tocilizumab in combination with MTX would provide greater benefit; this is being investigated in the European studies.

The results of this study confirmed that IL-6 plays a pathological role in the joint destruction in RA. IL-6 blockade can inhibit the osteoclast activation in RA. Additionally, tocilizumab therapy reduced MMP-3 levels (data not shown), which could also contribute to the radiographic benefit.

In addition to the radiographic benefits, tocilizumab monotherapy improved signs and symptoms as well as functional evaluation with MHAQ. Although this was an open-label study for clinical efficacy endpoints, the results of previous phase II studies $^{21} 22$ were confirmed. Moreover, significant improvement in MHAQ scores indicates that tocilizumab improves patients' daily living activity.

There was no decrease in the efficacy of tocilizumab during the 1-year treatment. The benefit of a humanised antibody was again emphasised in the repetitive treatment, as anti-tocilizumab antibodies were detected in only 4 patients $(2.5 \%)$ without requiring the use of immunosuppressive agents such as MTX. It could also be that tocilizumab that blocks IL- 6 action to induce B cell differentiation into antibody producing cells.

Tocilizumab monotherapy was generally well tolerated. There was no specific infection related to tocilizumab therapy, including tuberculosis, which is often a problem in anti-TNF therapy, ${ }^{30}$ although patients had neither prophylactic medication nor screening in this study.

Three malignancies occurred in patients treated with tocilizumab in this study. There are many reports describing the relationship between IL- 6 and malignant diseases, where IL-6 is often a causative factor. ${ }^{31}$ Further analysis to compare the incidence with an epidemiology surveillance data base regarding malignancies in Japanese patients with RA will be

Table 3 Adverse events observed in at least $5 \%$ of patients*

\begin{tabular}{lcc}
\hline & $\begin{array}{c}\text { Conventional } \\
\text { DMARDs }(\mathbf{n}=145)\end{array}$ & $\begin{array}{c}\mathbf{8} \mathbf{~ m g} / \mathbf{k g} \\
\text { Tocilizumab } \\
(\mathbf{n}=157)\end{array}$ \\
\hline Nasopharyngitis & $47(32.4)$ & $56(35.7)$ \\
Rash & $6(4.1)$ & $17(10.8)$ \\
Diarrhoea & $13(9.0)$ & $13(8.3)$ \\
Headache & $3(2.1)$ & $11(7.0)$ \\
Stomatitis & $13(9.0)$ & $9(5.7)$ \\
Eczema & $6(4.1)$ & $9(5.7)$ \\
Nausea & $2(1.4)$ & $9(5.7)$ \\
Pruritus & $2(1.4)$ & $9(5.7)$ \\
Paronychia & $1(0.7)$ & $9(5.7)$ \\
Vomiting & $5(3.4)$ & $8(5.1)$ \\
Vertebral compression fracture & $8(5.5)$ & $3(1.9)$ \\
\hline *Values are the number (\%) of patients. & \\
DMARDs, disease-modifying antirheumatic drugs; Tocilizumab, humanised \\
anti-interleukin-6 receptor antibody.
\end{tabular}

required to ascertain the carcinogenesis risk or the benefit of IL6 inhibition.

The increase in TC is also observed in anti-TNF therapy ${ }^{32}$ and therefore it could be secondary to the improvement in inflammation. We have reported that tocilizumab treatment improves wasting in Castleman's disease, an atypical lymphoproliferative disease with overproduction of IL- 6 but not TNF $\alpha$, where tocilizumab monotherapy normalises hypocholesterolemia but seldom causes hypercholesterolemia. ${ }^{33}$ Therefore, IL-6 plays a role in regulating serum cholesterol levels.

As an increase in serum IL- 6 levels has been reported as a cardiovascular risk ${ }^{34}$ and as IL- 6 could contribute to the atherosclerosis, ${ }^{35}$ it is of interest whether tocilizumab therapy reduces the incidence of cardiovascular events. This issue will be also proven in a future epidemiological surveillance of patients treated long-term with tocilizumab.

In conclusion, this study clearly demonstrates the superiority of tocilizumab monotherapy in preventing joint damage to conventional DMARDs in Japanese RA patients. However the results need to be confirmed in the trials in western RA patients.

\section{ACKNOWLEDGEMENTS}

The authors wish to thank the members of MRA clinical study group for the treatment and Takahiro Kakehi BSc, Tatsuya Horiguchi BSc, and Paul Langman PhD for their valuable assistance with the design and analysis of the study and preparation of this manuscript. This work was supported by Chugai Pharmaceutical Co., Ltd., Tokyo, Japan.

\section{Authors' affiliations \\ Norihiro Nishimoto, Jun Hashimoto, Tadamitsu Kishimoto, Osaka University, Osaka, Japan \\ Nobuyuki Miyasaka, Tokyo Medical \& Dental University, Tokyo, Japan Kazuhiko Yamamoto, University of Tokyo, Tokyo, Japan \\ Shinichi Kawai, Toho University Omori Medical Center, Tokyo, Japan Tsutomu Takeuchi, Saitama Medical Center/School, Saitama, Japan \\ Norikazu Murata, Kyowakai Hospital, Osaka, Japan \\ Désirée van der Heijde, University Hospital Maastricht, Maastricht, The Netherlands}

Competing interests: NN has served as a consultant to and/or received honoraria from Chugai Pharmaceutical, the manufacture of tocilizumab. TK holds a patent for tocilizumab. The other authors have no competing interests.

\section{REFERENCES}

1 Harris ED Jr. Rheumatoid arthritis: Pathophysiology and implications for therapy. N Engl J Med 1990;322:1277-89.

2 Nishimoto N. Interleukin-6 in rheumatoid arthritis. Curr Opin Rheumatol 2006;18:277-81.

3 Nakahara H, Song J, Sugimoto M, Hagihara K, Kishimoto T, Yoshizaki K, et al. Anti-interleukin-6 receptor antibody therapy reduces vascular endothelial growth factor production in rheumatoid arthritis. Arthritis Rheum 2003;48:1521-9.

4 Tamura T, Udagawa N, Takahashi N, Miyaura C, Tanaka S, Yamada Y, et al. Soluble interleukin-6 receptor triggers osteoclast formation by interleukin 6. Proc Natl Acad Sci USA 1993;90:11924-8.

5 Kotake S, Sato K, Kim KJ, Takahashi N, Udagawa N, Nakamura I, et al. Interleukin-6 and soluble interleukin-6 receptors in the synovial fluids from rheumatoid arthritis patients are responsible for osteoclast-like cell formation. $J$ Bone Mineral Res 1996; 11:88-95.

6 Hirano T, Matsuda T, Turner M, Miyasaka N, Buchan G, Tang B, et al. Excessive production of interleukin $6 / B$ cell stimulatory factor-2 in rheumatoid arthritis. Eur J Immunol 1988;18:1797-801.

7 Houssiau FA, Devogelaer JP, Van Damme J, de Deuxchaisnes CN, Van Snick J. Interleukin- 6 in synovial fluid and serum of patients with rheumatoid arthritis and other inflammatory arthritides. Arthritis Rheum 1988;31:784-8.

8 Guerne PA, Zuraw BL, Vaughan JH, Carson DA, Lotz M. Synovium as a source of interleukin 6 in vitro. Contribution to local and systemic manifestations of arthritis. $\mathrm{J}$ Clin Invest 1989;83:585-92.

9 Miyasaka N, Sato K, Hashimoto J, Kohsaka H, Yamamoto K, Goto M, et al. Constitutive production of interleukin $6 / \mathrm{B}$ cell stimulatory factor-2 from inflammatory synovium. Clin Immunol Immunopathol 1989;52:238-47.

10 Bhardwaj N, Santhanam U, Lau LL, Tatter SB, Ghrayeb J, Rivelis M, et al. IL-6/ IFN-beta 2 in synovial effusions of patients with rheumatoid arthritis and other arthritides. J Immunol 1989; 143:2153-9. 
11 Dasgupta B, Corkill M, Kirkham B, Gibson T, Panayi G. Serial estimation of interleukin 6 as a measure of systemic disease in rheumatoid arthritis. J Rheumatol 1992;19:22-5.

12 Madhok R, Crilly A, Watson J, Capell HA. Serum interleukin 6 levels in rheumatoid arthritis: correlations with clinical and laboratory indices of disease activity. Ann Rheum Dis 1993;52:232-4.

13 Sack U, Kinne RW, Marx T, Heppt P, Bender S, Emmrich F. Interleukin-6 in synovial fluid is closely associated with chronic synovitis in rheumatoid arthritis. Rheumatol Int 1993;13:45-51.

14 Uson J, Balsa A, Pascual-Salcedo D, Cabezas JA, Gonzalez-Tarrio JM, MartinMola E, et al. Soluble interleukin 6 (IL-6) receptor and IL-6 levels in serum and synovial fluid of patients with different arthropathies. J Rheumatol 1997; 24:2069-75

15 Roux-Lombard P, Eberhardt K, Saxne T, Dayer JM, Wollheim FA. Cytokines, metalloproteinases, their inhibitors and cartilage oligomeric matrix protein: relationship to radiological progression and inflammation in early rheumatoid arthritis. A prospective 5-year study. Rheumatology $2001 ; 40: 544-51$.

16 Yamanaka H, Matsuda Y, Tanaka M, Sendo W, Nakajima H, Taniguchi A, et al. Serum matrix metalloproteinase 3 as a predictor of the degree of joint destruction during the six months after measurement, in patients with early rheumatoid arthritis. Arthritis Rheum 2000;43:852-8.

17 Ribbens C, Andre B, Jaspar JM, Kaye O, Kaiser MJ, De Groote D, et al. Matrix metalloproteinase-3 serum levels are correlated with disease activity and predict clinical response in rheumatoid arthritis. J Rheumatol 2000;27:888-93.

18 Sato K, Tsuchiya M, Saldanha J, Koishihara Y, Ohsugi Y, Kishimoto T, et al. Reshaping a human antibody to inhibit the interleukin 6-dependent tumor cell growth. Cancer Res 1993;53:851-6.

19 Choy EHS, Isenberg DA, Garrood T, Farrow S, loannou Y, Bird H, et al. Therapeutic benefit after blocking interleukin- 6 activity in rheumatoid arthritis with an anti-interleukin-6 receptor monoclonal antibody. Arthritis Rheum 2002;46:3143-50.

20 Nishimoto N, Yoshizaki K, Maeda K, Kuritani T, Deguchi H, Sato B, et al Toxicity, pharmacokinetics, and dose-finding study of repetitive treatment with the humanized anti-interleukin 6 receptor antibody MRA in rheumatoid arthritis. Phase I/II clinical study. J Rheumatol 2003;30:1426-35.

21 Nishimoto N, Yoshizaki K, Miyasaka N, Yamamoto K, Kawai S, Takeuchi T, et al. Treatment of rheumatoid arthritis with humanized anti-interleukin-6 receptor antibody: a multicenter, double-blind, placebo-controlled trial. Arthritis Rheum 2004;50:1761-9

22 Maini RN, Taylor PC, Szechinski J, Pavelka K, Broll J, Balint G, et al. Doubleblind randomized controlled clinical trial of the interleukin- 6 receptor antagonist, tocilizumab, in European patients with rheumatoid arthritis who had an incomplete response to methotrexate. Arthritis Rheum 2006;54:2817-29.

23 Arnett FC, Edworthy SM, Bloch DA, McShane DJ, Fries JF, Cooper NS, et al. The American Rheumatism Association 1987 revised criteria for the classification of rheumatoid arthritis. Arthritis Rheum 1988;31:315-24.

24 van der Heijde D. How to read radiographs according to the Sharp/van der Heijde method. J Rheumatol 2000;27:261-3.

25 van der Heijde D, Simon L, Smolen J, Strand V, Sharp J, Boers M, et al. How to report radiographic data in randomized clinical trials in rheumatoid arthritis: guidelines from a roundtable discussion. Arthritis Rheum 2002;47:215-8.

26 Kashiwazaki S, Ichikawa Y, Sugawara S, Nagaya I, Kawai S, Hakota M, et al. Determination of the clinical optimal dose of L-377 (methotrexate capsule) for the treatment of rheumatoid arthritis. Ensyo 1996;16:437-58

27 Ito S, Gross WL, Reinhold-Keller E, Gause A, Aries P, Ruther W, et al. Rheumatology in Japan, Germany, and Egypt: a comparison of medical practices. Acta Medica et Biologica 2006;54:51-58.

28 Fransen J, Creemers MC, Van Riel PL. Remission in rheumatoid arthritis: agreement of the Disease Activity Score (DAS28) with the ARA preliminary remission criteria. Rheumatology 2004;43:1252-5.

29 Kosinski M, Zhao SZ, Dedhiya S, Osterhaus JT, Ware JE Jr. Determining minimally important changes in generic and disease-specific health-related quality of life questionnaires in clinical trials of rheumatoid arthritis. Arthritis Rheum 2000;43:1478-87.

30 Keane J, Gershon S, Wise RP, Mirabile-Levens E, Kasznica J, Schwieterman WD, et al. Tuberculosis associated with infliximab, a tumor necrosis factor alphaneutralizing agent. N Engl J Med 2001;345:1098-104.

31 Akira S, Taga T, Kishimoto T. Interleukin-6 in biology and medicine. Adv Immunol 1993;54:1-78

32 Seriolo B, Paolino S, Sulli A, Fasciolo D, Cutolo M. Effects of Anti-TNF- $\alpha$ Treatment on Lipid Profile in Patients with Active Rheumatoid Arthritis. Ann N Y Acad Sci 2006;1069:414-9.

33 Nishimoto N, Kanakura Y, Aozasa K, Johkoh T, Nakamura M, Nakano S, et al. Humanized anti-interleukin- 6 receptor antibody treatment of multicentric Castleman disease. Blood 2005; 106:2627-32

34 Fisman EZ, Benderly M, Esper RJ, Behar S, Boyko V, Adler Y, et al. Interleukin-6 and the risk of future cardiovascular events in patients with angina pectoris and/ or healed myocardial infarction. Am J Cardiol 2006;98:14-8

35 Rattazzi M, Puato M, Faggin E, Bertipaglia B, Zambon A, Pauletto P. C-reactive protein and interleukin- 6 in vascular disease: culprits or passive bystanders? J Hypertens 2003;21:1787-803.

\section{Take advantage of BMJ Journals' remarkable catalogue of titles with Related} Collections

No busy professional has time to browse through all pertinent journals to find relevant articles, but with Related Collections you no longer have to. Follow the "Related Collections" link from any article and use the "Show Collections from other Journals" to expand your search across all BMJ Journals. Or simply follow the "Browse by topic" link on the home page. By setting up your own collections and receiving email alerts every time an article is added to your chosen area, you can build up your own significant body of knowledge. 